\title{
Relationship Between Maternal Nutritional Status and Birth Outcome Among Pregnant Women Attending Antenatal Clinic at Yusuf Dantsoho Memorial Hospital Kaduna
}

\author{
Safiya Aliyu Tijjani ${ }^{1, *}$, Maimuna Ladidi Aliyu", Kudirat Afolabi ${ }^{2}$ \\ ${ }^{1}$ Department of Nutrition and Dietetics, Kaduna Polytechnic, Kaduna, Nigeria \\ ${ }^{2}$ Department of Food Technology, Kaduna Polytechnic, Kaduna, Nigeria \\ Email address: \\ safiyaaliyutijjani@gmail.com (S. A. Tijjani), maimunaba@yahoo.com (M. L. Aliyu), afolabikuddy@gmail.com (K. Afolabi) \\ ${ }^{*}$ Corresponding author
}

To cite this article:

Safiya Aliyu Tijjani, Maimuna Ladidi Aliyu, Kudirat Afolabi. Relationship Between Maternal Nutritional Status and Birth Outcome Among Pregnant Women Attending Antenatal Clinic at Yusuf Dantsoho Memorial Hospital Kaduna. Journal of Family Medicine and Health Care. Vol. 6, No. 3, 2020, pp. 62-65. doi: 10.11648/j.jfmhc.20200603.11

Received: February 17, 2020; Accepted: February 27, 2020; Published: June 4, 2020

\begin{abstract}
This study was undertaken to find out the relationship between maternal dietary pattern, anthropometric indices with birth outcome among pregnant women in their $3^{\text {rd }}$ trimester attending antenatal clinic at Yusuf Dantsoho Memorial Hospital, Tudun Wada, Kaduna. Sixty-seven mothers - baby pair participated in the study. Weight, height, and Mid Upper Arm Circumference (MUAC) of mothers were measured with unclothed newborn length, weight, head and chest circumference also taken. Results obtained shows mean maternal age, weight, height, and MUAC of $31.20 \pm 8.40$ years, $70.37 \pm 12.73 \mathrm{~kg}$, $1.620 \pm 0.07 \mathrm{~m}, 26.65 \pm 4.08 \mathrm{~cm}$, and $26.63 \pm 3.80 \mathrm{~kg} / \mathrm{m}^{2}$ respectively. Majority of the pregnant women $(77.60 \%)$ had good nutritional status while $16.40 \%, 6.00 \%$ are moderately and severely malnourished respectively. Maternal dietary pattern showed daily to weekly intake of all the food groups with less than $50 \%$ except for bread and cereals which is more than $50 \%$. Maternal mean intake of total protein and total calories was close to the recommended daily intake of $60-75 \mathrm{~kg} / \mathrm{day}$, and 2500 $-3000 \mathrm{kcal}$ respectively. Newborn anthropometric measurements indicated that $61.20 \%$ were mildly stunted, $70.10 \%$ mildly underweight, and $62.70 \%$ moderately wasted neonates. Head and chest circumference are within the normal range. Maternal anthropometry and dietary pattern showed a positive correlation with birth outcome.
\end{abstract}

Keywords: Maternal, Dietary, Anthropometric, Women, Kaduna

\section{Introduction}

Malnutrition is a problem among women which poses a great challenge that make maternal ill-health a global burden which needs to be addressed [1]. Malnutrition is one of the major cause of maternal mortality and determinant of a successful pregnancy and birth outcome. The relationship between maternal nutrition and birth outcome is conflicting and intermingled by many factors like biological, socioeconomic, and demographic factors [2, 3]. Consequential effect of maternal malnutrition does not just affect the pregnant woman but also has a devastating effect on the fetus, unfortunately in developing countries, pregnant women are nutritionally the most insecure group and many expectant mothers do not receive optimum level of essential nutrients during their gestational period $[4,5]$.

Nearly 4 million newborns die within 28 days of birth (Population Reference Bureau 2006; WHO 2012; Addai 2010) with more millions suffering from, disease, infection, injury and disability [6]. Almost equal percent (98\%) of the world neonatal deaths and stillbirths are from developing countries, while the highest proportion are from sub-Saharan Africa [7]. According to UNICEF, more than half a million women die from causes related to pregnancy and childbirth yearly. Maternal mortality rate for a woman in the developing countries is 300 times greater than for women living in the developed countries [8]. Ninety-five percent $(95 \%)$ of the world's maternal mortality are from Africa and Asia with precisely $50 \%$ of the global total coming from Sub-Saharan Africa and 35\% from South Asia. In 2008, maternal death 
ratio in Kaduna city was $800 / 100,000$ live births which is, about 1 death for every 125 pregnant women. In 2003, the North West zone has the highest proportion (27 percent) of children reported weighing less than $2.5 \mathrm{~kg}$ at birth, more than a third ( 36 percent) of children whose birth weights are known in Kaduna weighed less than $2.5 \mathrm{~kg}$ at births. Infant mortality rate in Kaduna city was 115 per 1,000 live births [9]. Although, research findings on the importance of maternal nutrition to fetal development and birth outcomes has obviously been demonstrated in experimental animal studies [10], the findings of studies in humans are much less dependable, due, to secondary factors that differ from study to study like baseline maternal nutritional status, socioeconomic status of the study population, timing and methods of assessing maternal nutritional variables. In addition, there is presently no data on dietary pattern, nutritional status and birth outcome among pregnant women in Kaduna, Nigeria. This study tends to investigate the relationship between dietary pattern, nutritional status and birth outcome among pregnant mothers attending antenatal clinic at Yusuf Dantsoho Memorial Hospital Kaduna.

\section{Materials and Methods}

\subsection{Study Area}

Kaduna is located at 10.52641 latitude, and 7.43879 longitudes and situated at an elevation of 626 meters above sea level. The urban part of the city largely lies in Kaduna North, South and Chikun local government. According to the 2006 census the population of Kaduna city was 1,139578 and recently reprojected to 1,582102 people in 2015 [9]. Tudun Wada district is located in Kaduna south local government with co-ordinate 10"30'45" N and 7'24'40" E. Yusuf Dantsoho memorial hospital, formerly known as Asibitin Dutse was founded in 1975 and one of the largest government owned hospital situated at Tudun wada district along Polytechnic road.

\subsection{Study Population}

The study involves pregnant women in third trimester of pregnancy (32 - 40wks), and has been attending the antenatal clinic at least in their second trimester of pregnancy (1628wks) with hemoglobin levels and weight recorded at Yusuf Dantsoho Memorial Hospital, Kaduna.

\subsection{Inclusion Criteria}

All singleton pregnant women between the ages of 16-49 years, who has no medical risk pregnancy and antenatal care either in their first or second trimester were enrolled for the study

\subsection{Exclusion Criteria}

Pregnant women who had first antenatal care attendance during the third trimester, with medical complications during their pregnancy, and those with multiple pregnancies were excluded from the study.

\subsection{Sampling Technique}

Yusuf Dantsoho Hospital, a government owned hospitals was purposively selected for the study, due to its affordable cost of services, popularity and high level of attendance by pregnant women, with average antenatal population of about 180 per month. Most women in the communities irrespective of their socioeconomic status residing in the area attend the hospital. Following every antenatal clinic and the inclusion criteria all eligible subject were purposively selected.

\subsection{Sample Size}

One hundred and six pregnant women in third trimester were enlisted for the study and at the end of fourth month of the study, sixty-seven mothers - baby's pairs completed the study

\subsection{Data Collection}

Data was collected through use of validated semistructured for dietary assessment, and maternal energy intake by food frequency questionnaires and 24 hours dietary recall. Maternal anthropometry was obtained through weight, height and Mid Upper Arm Circumference (MUAC) as described by Corgill [11]. Neonatal nutritional status was assessed using methods of Fareeha and compared with WHO Z-score standard using Anthro Software version 14 [12].

\subsection{Maternal Nutritional Status}

Records of weight, and height, during the first and second trimesters of the pregnant women were obtained from the maternal health record card. UNICEF Seca scale was used to determine the maternal weight (in $\mathrm{kg}$ ) during the study period while height was measured $(\mathrm{cm})$ using height-o-meter. MUAC was also taken at every antenatal visit, using a measuring tape. MUAC reading below $21 \mathrm{~cm}$ signifies severe malnutrition; those between 21-23 cm have mildly malnutrition status or borderline nutritional status; and measurement above $23 \mathrm{~cm}$ signifying a healthy nutritional status.

\subsection{Neonatal Nutritional Status}

Birth weight of the babies born to the respondent at home were measured by the researcher using infant pan scale, those with hospital delivery were recorded from the hospital records whereas length were taken by infant-o-meter. Head, chest and MUAC measurements was carried out using a nonstretchable measuring tape. The outcome was compared with the standard WHO Z-score for weight for height, head and chest circumference.

\subsection{Dietary Assessment}

Dietary assessment was carried out in a face-to-face interview with pregnant women that participated in the study, using a validated Food Frequency Questionnaire (FFQ) originally developed by national cancer institute. The FFQ 
consists of eight food groups adopted from Food Guide Pyramid and 24-hour dietary recall (DR) in order to assess the frequency of consumption of specific food or category of foods [13].

\section{Results and Discussion}

Table 1 shows dietary intake of pregnant women using 24 hours' dietary recall. Mean total carbohydrates intake is $210.51 \pm 75.90 \mathrm{~g} /$ day which was higher than the recommended daily intake of $175.00 \mathrm{~g} /$ day and mean protein intake is $45.05 \pm 39.00 \mathrm{~g} /$ day which was within recommended intake (45-60 g/day). Maternal fat intake $65.18 \pm 39.10$ was also within the reference range. Maternal mean total caloric intake was $2527.51 \pm 764.90 \mathrm{~g} /$ day intake was within recommended daily intake range of $2500-3000 \mathrm{kcal} /$ day.

Table 1. Nutrient Intakes of Pregnant Women Using 24hrs Recall

\begin{tabular}{lll}
\hline Nutrients Intake & $\begin{array}{l}\text { Respondent } \\
\text { Nutrients Intake }\end{array}$ & RDI* \\
\hline Total Carbohydrate (g/day) & $210.51 \pm 75.90$ & $175-190(+450)$ \\
Total Protein (g/day) & $45.05 \pm 39.00$ & $60-75(1.02 \mathrm{~g} / \mathrm{kg} /$ day $)$ \\
Total Fat (g/day) & $65.18 \pm 39.10$ & $45-60$ \\
Total Kcalories (kcal/day) & $2527.51 \pm 764.90$ & $2500-3000(+452)$ \\
\hline
\end{tabular}

Values as Mean \pm SD.*RDI-Recommended Daily Intake.

Table 2 indicates that high mean caloric intakes of $3121.16 \pm 340.11 \mathrm{kcal} /$ day was obtained from mothers that gave birth to larger babies, while those mothers with lower mean caloric intake of $1485.86 \pm 723.45 \mathrm{~g}$ /day had low birth weight babies. These values obtained based on birth weight for caloric intake were statistically different $(\mathrm{p}-<0.05)$.

Table 2. Maternal Mean Caloric Intake with Newborn Birth Weight

\begin{tabular}{ll}
\hline Birth Weight Classification & Maternal Mean Caloric Intakes \\
\hline$<2.5 \mathrm{~kg}$ & $1485.86 \pm 723.45^{\mathrm{a}}$ \\
$2.5-3.99 \mathrm{~kg}$ & $2596.57 \pm 221.46^{\mathrm{b}}$ \\
$>4.0 \mathrm{~kg}$ & $3121.16 \pm 340.11^{\mathrm{c}}$ \\
\hline
\end{tabular}

Values are Mean \pm SD., Values with different superscript are considered significance different $(\mathrm{p}<0.05)$.

The results on the frequency of consumption of the various food groups show that $43.30 \%$ of mothers consumed rice $4-5$ $\mathrm{x} /$ week, followed by $35.80 \%$ mothers who consumed rice 6 $\mathrm{x} /$ week likewise $43.30 \%$ of pregnant women consumes millet 4-5 x/week. Yam (47.90\%) and sweet potatoes $(40.30 \%)$ are the most frequently (2-3 x/week, 6x/week respectively) consumed food in the Root and Tubers food group in this same group locally made spaghetti has the highest percentage $(44.80 \%)$ of pregnant women with high level of consumption of $6 \mathrm{x} /$ week. Different types of cooking oil are consumed but palm oil and animal fat ("Manshanu, Kakide") are most frequently consumed by $25.40 \%$ of the mothers. Also Vegetable oil consumption was by high percent of respondent $(53.70 \%)$ at $6 \mathrm{x} /$ week. Baobab leaves was the most frequently (4-5 x/day) consumed vegetable soup by $35.80 \%$ of mothers, followed by fluted pumpkin leaves which was $31.30 \%$ was consumes $2-3 \mathrm{x} /$ week by the pregnant women.
Moringa leaves was consumed $4-5 \mathrm{x} /$ week by $26.90 \%$ mothers. Fruits was least consumed by the pregnant women, only $35.80 \%$, takes orange $4-5 \mathrm{x} /$ week. Local drinks like tigernut was frequently consumed (4-5 x/week) by $46.30 \%$ of the mothers, followed by $46.30 \%$ that consume scourrel drink $6 \mathrm{x} /$ week. The frequency of consumption also indicates that $37.30 \%$ of mothers take fish once /day, while $23.90 \%$ takes chicken once/week followed by $32.50 \%$ that took egg once/day. Only $41.80 \%$ of the pregnant women takes soybeans $6 \mathrm{x} /$ week and more than half $(53.70 \%)$ of the mothers takes powdered milk $6 \mathrm{x} /$ week, while $37.30 \%$ consumes yoghurt $6 \mathrm{x} /$ week.

Figure 1 indicates that most of the mothers $(77.60 \%)$ were within the normal MUAC cut off $\geq 23.1 \mathrm{~cm}$ while $16.40 \%$ were moderately malnourished $(\geq 19.00-<23.00 \mathrm{~cm})$ and $6 \%$ severely malnourished $(<19.00)$. Table 3 shows the average weight, height value among the pregnant women as $70.37 \pm 12.70 \mathrm{~kg}$, and $1.62 \pm 0.09 \mathrm{~m}$ respectively. Equal percentage $(17.90 \%)$ of pregnant women from different age range 25 - 29, 35 - 39, 44 - 49 years, had more weight with mean value as $70.20 \pm 13.3,71.11 \pm 14.9$. and $74.8 \pm 11.3 \mathrm{~kg}$ respectively. Means in the same column with different superscript are considered significantly different $(p<0.05)$.

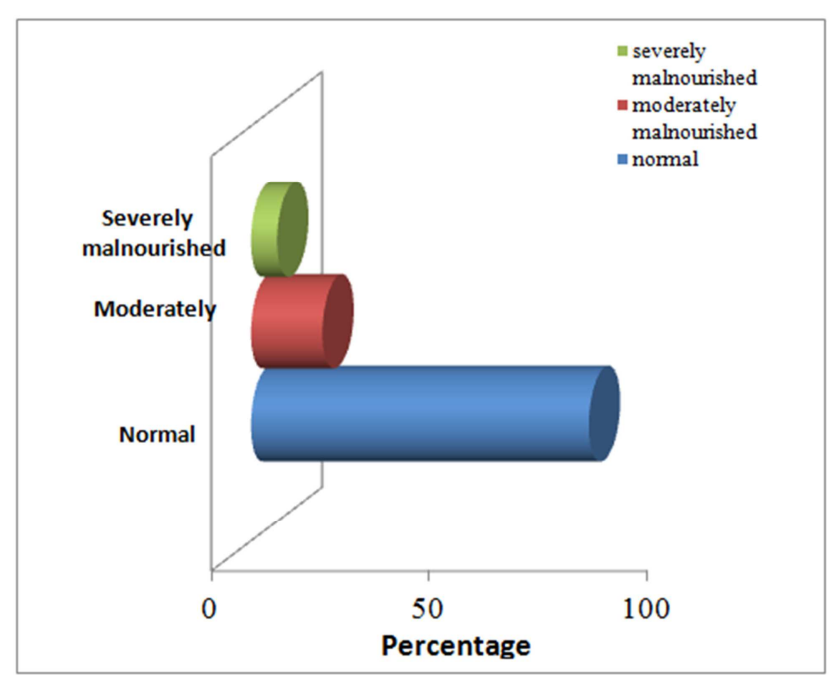

Figure 1. Percentage Distribution of Nutritional Status of Women Using $M U A C$.

Table 3. Distribution of Weight, and Height according to Age among Pregnant Women in their Third Trimester.

\begin{tabular}{lllll}
\hline Age & $\begin{array}{l}\text { Frequency } \\
\text { (years) }\end{array}$ & $\begin{array}{l}\text { Percentage } \\
(\%)\end{array}$ & Weight $(\mathbf{k g})$ & Height (m) \\
\hline $15-24$ & 7 & 10.4 & $66.94 \pm 12.71^{\mathrm{a}}$ & $1.65 \pm 0.11^{\mathrm{a}}$ \\
$20-24$ & 10 & 14.9 & $66.09 \pm 11.80^{\mathrm{a}}$ & $1.62 \pm 0.09^{\mathrm{a}}$ \\
$25-29$ & 12 & 17.9 & $70.20 \pm 13.31^{\mathrm{b}}$ & $1.71 \pm 0.10^{\mathrm{b}}$ \\
$30-34$ & 11 & 16.4 & $68.1 \pm 09.90^{\mathrm{a}}$ & $1.65 \pm 0.09^{\mathrm{a}}$ \\
$35-39$ & 12 & 17.9 & $71.11 \pm 14.91^{\mathrm{b}}$ & $1.62 \pm 0.08^{\mathrm{a}}$ \\
$40-44$ & 3 & 17.9 & $74.8 \pm 11.42^{\mathrm{c}}$ & $1.62 \pm 0.06^{\mathrm{a}}$ \\
$45-49$ & 3 & 4.5 & $80.8 \pm 20.01^{\mathrm{d}}$ & $1.62 \pm 0.07^{\mathrm{a}}$ \\
Mean \pm SD & 67 & 100 & $70.37 \pm 12.7$ & $1.62 \pm 0.09$ \\
\hline
\end{tabular}

Values are mean \pm SD., Means in the same column with different superscript are considered significantly different $(\mathrm{p}<0.05)$. 
Mothers who consumed calories $<1500 \mathrm{kcal} / \mathrm{d}$ during the last trimester delivered low birth weight neonates. Similarly, results findings have showed that mean intake of maternal macronutrient were within recommended daily intake (2500 - $3000 \mathrm{kcal} /$ day) with regard to protein and energy intake were reported by Gopalan et. al., [14]. Kramer reports a study in Maryland on 300 pregnant women that show a significant relationship between energy intake and birth weight [15]. It was observed that pregnant mothers regardless of their nutritional status were consuming less than recommended servings of various food groups. Mean intake of only bread and cereal group was more than recommended servings per day $(6-11 \mathrm{x} /$ week $)$. Rice and millet are the common meal consumed. Intake of chicken, and meat was associated with the socioeconomic status. Fish (sardines, geisha, mackerel etc) are most consumed among the pregnant women, however chicken was the least consumed. Only a few of pregnant women ate organ meat once a day. Consumption of other food groups like fruit, vegetables, milk and meat was below the recommended servings per day. This trend of food group intake among the pregnant women is reflecting the dietary habits of the study population. Women are not used to consumptions of milk and fruit in every day meal, while carbohydrates and fats are the main components of the daily cooking. This is in agreement with findings on eating habits of Pakistanis based on their Perceptions and preferences [12]. Inadequate intake of protein rich foods cannot meet the increase demand for energy and protein in the third trimester to support both the growth of her baby and her own health to prevent anemia during pregnancy and low birth weight babies.

\section{Conclusion}

Based on the findings of this study it is concluded that intake of fruits and vegetables is low among the study population. The pregnant women anthropometry shows that most have a good nutritional status. About one third of the pregnant women were anemic. Male newborn had higher height, weight, head and chest circumference than female. Women should be enlightened more on pregnancy risk factors and of the importance of stating antenatal clinic early in pregnancy.

\section{References}

[1] NDHS (2013) Nigerian Demographic and Health Survey. Calverton, Maryland: National population Commission, Abuja - Nigeria and ORC/Macro. Nigeria Abuja, Nigeria.
[2] Villar J., Belizan JM., (2003) The contribution of fetal growth and premature babies to low birth weight babies in developing societies. American Medical Journal Obstetric Gynecology. 46 (4); 231-6.

[3] Blumenshine A., Cellic N. (2010); Pregnancy and Lactation Among Urban Poor in Africa. National Academy Press. Washington D. C. 73: 61 And 108.

[4] WHO (2012), Maternal, newborn, child and adolescent health: care of the preterm and/or low- birth-weight newborn. World Health Organization.

[5] Tianan J, Parul C, Subarna K. K, Lee W, Keith PW. (2005); Micronutrient deficiencies in early pregnancy are common, concurrent and vary by season among rural nepali pregnant women. Journal Nutrition 135: 1106-12.

[6] Addai, M. (2010), Prevelance and Determinant of Maternal and Child Malnutrition in West Africa, Micronutrient the Hidden Hunger, The Multiethnic Cohort Study. Journal Nutrition 135 (4): 843.

[7] Kazaura, M. R., Kidanto, H. L. \& Massawe, S. N. (2011). Levels, Trends and Risk for Early Neonatal Mortality at Muhimbili National Hospital, Tanzania. East African Journal of Public Health 3, 10-13.

[8] UNICEF (2011) Malaysia: The Millennium Development goal at 2010. Kuala Lampur: United Nation Country team. Malatsia.

[9] NURHI. Nigerian Urban Reproductive Health Initiative (2014). Kaduna. http/www.nurhitoolkit.org. Of Maternal Death: A Systematic Review. Lancet.; 367 (9516): 1066-74.

[10] Northstone K, Emmett P, Rogers I. (2011). Dietary patterns in pregnancy and associations with socio-demographic and lifestyle factors. European Journal Clinical Nutrition. 62 (4): 471-9.

[11] Corgill Bruce. (2003): Anthropometry Indicator Measurement Guide. Washington. DC: Food and Nutrition Technical Assistance (FANTA) Project, FHI 36.

[12] Fareeha S., Fariha Z., Rubina H, Abdul B., Asher F. And Akhtar H. (2014)., Maternal Dietary Intake and Anthropometric Measurements of Newborn at Birth Diabetes Journal, 7, 14-19.

[13] Song YP, Suzanne PM, Lynne RW, (2005); Dietary patterns using the food guide pyramid groups are associated with socio-demographic and lifestyle factors: the multiethnic cohort study. Journal Nutrition. 135 (4): 843-9.

[14] Gopalan C, Ramasastri BV, Balasubramanian SC. (2002) Nutritive Value of Indian Food. Hyderabad: National Institute of Nutrition, ICMR.

[15] Kramer, S. M. (2003). The Epidemiology of Adverse Pregnancy Outcomes: An Overview. Journal Nutrition, 12 (3): 133-140. 